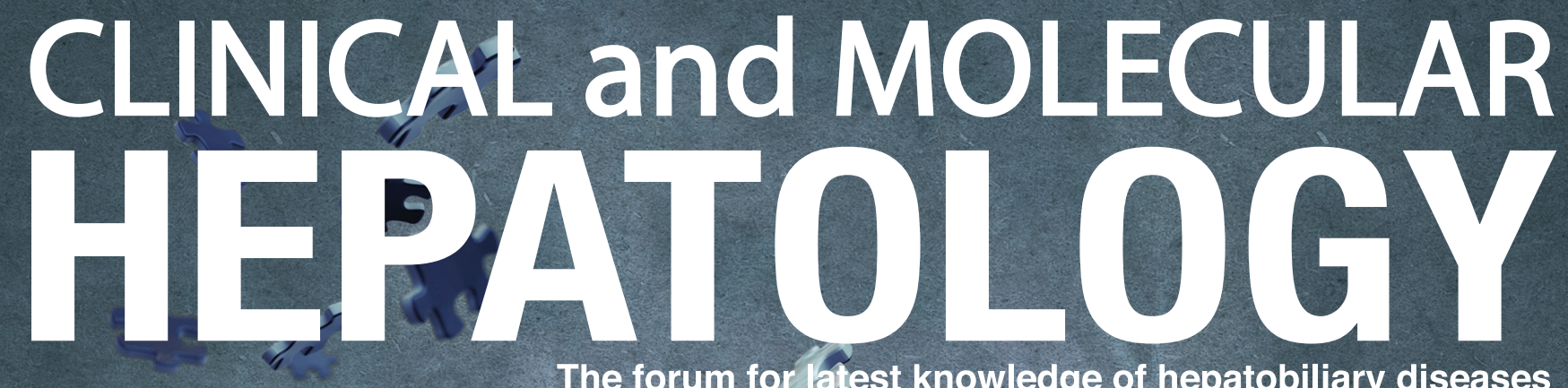

The forum for latest knowledge of hepatobiliary diseases

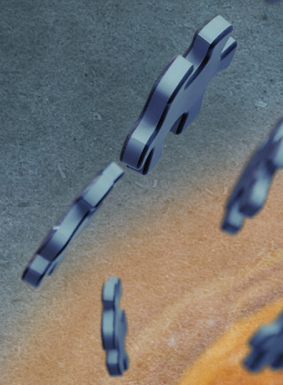

is

$$
\text { (n) }
$$

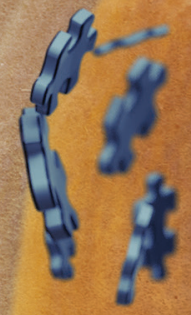

Fatty liver and risk of olementia

NAFLD increases a risk of siroke

DPP-4 inhibitor-specinic biornarkers in NAFID

LPS promotes HCC by NEE IS formation via TLRS4

CLIF-SOFA score and sepsis

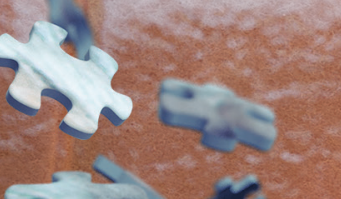




\title{
Crosstalk between tumor-associated macrophages and neighboring cells in hepatocellular carcinoma
}

\author{
Pil Soo Sung ${ }^{1,2}$ \\ ${ }^{1}$ The Catholic University Liver Research Center, College of Medicine, The Catholic University of Korea, Seoul; ${ }^{2}$ Division of \\ Gastroenterology and Hepatology, Department of Internal Medicine, Seoul St. Mary's Hospital, College of Medicine, The Catholic \\ University of Korea, Seoul, Korea
}

The tumor microenvironment generally shows a substantial immunosuppressive activity in hepatocellular carcinoma (HCC), accounting for the suboptimal efficacy of immune-based treatments for this difficult-to-treat cancer. The crosstalk between tumor cells and various cell types in the tumor microenvironment is strongly related to HCC progression and treatment resistance. Monocytes are recruited to the HCC tumor microenvironment by various factors and become tumor-associated macrophages (TAMs) with distinct phenotypes. TAMs often contribute to weakened tumor-specific immune responses and a more aggressive phenotype of malignancy. Recent single-cell RNA-sequencing data have demonstrated the central roles of specific TAMs in tumorigenesis and treatment resistance by their interactions with various cell populations in the HCC tumor microenvironment. This review focuses on the roles of TAMs and the crosstalk between TAMs and neighboring cell types in the HCC tumor microenvironment. (Clin Mol Hepatol 2022;28:333-350)

Keywords: Carcinoma, Hepatocellular; Immunotherapy; Tumor-associated macrophages; Tumor microenvironment

\section{INTRODUCTION}

Hepatocellular carcinoma (HCC) accounts for nearly 800,000 deaths worldwide.' In 2018, the estimated incidence of HCC in South Korea was 21.2 per 100,000 person-years, representing the fifth and sixth most common cancer in men and women, respectively. ${ }^{2}$ HCC is associated with inflammation and stems from chronic hepatic injury.' Worldwide, the incidence and mortality of nonalcoholic steatohepatitis (NASH)-related HCC are increasing, reflecting an increasing prevalence of obesity. ${ }^{3}$ Although early-stage HCC can be treated with surgical resection and locoregional treatments, such as percutaneous ablation, the disease is frequently diagnosed at an advanced stage. $\mathrm{HCC}$ is managed by palliative systemic therapy in such cases, which in the past 10 years have relied primarily on the tyrosine kinase inhibitor (TKI) sorafenib. ${ }^{4}$ Recently, several TKIs for the first- and second-line management for advanced HCC, including lenvatinib, cabozantinib, and regorafenib, have been approved and are now clinically used.

Immune-based HCC treatments have various clinical advantages beyond their high response rates. One benefit is related to the quality of life. Patient-reported outcome data have demonstrated improved quality of life with atezolizum-

\footnotetext{
Corresponding author : Pil Soo Sung

Division of Gastroenterology and Hepatology, Department of Internal Medicine, College of Medicine, Seoul St. Mary's Hospital, The Catholic University of Korea, 222 Banpo-daero, Seocho-gu, Seoul 06591, Korea 
ab plus bevacizumab treatment compared to that with sorafenib. ${ }^{5}$ Nivolumab was recently approved as a secondline therapy, and atezolizumab plus bevacizumab were shown to be superior to sorafenib as primary treatment for advanced HCC. ${ }^{6}$ However, the first approved antiprogrammed death (PD)-1 antibody, nivolumab, has an objective response rate (ORR) of $<20 \%$ in $\mathrm{HCC}^{7.8}$ The Checkmate- 040 study of unresectable HCC revealed that programmed deathligand 1 (PD-L1) expression in $>1 \%$ of tumor cells is associated with a $28 \%$ ORR for nivolumab, compared with a $16 \%$ ORR with PD-L1 expression in $<1 \%$ of tumor cells. These findings need to be validated because the expression of PD-L1 in nonparenchymal cells was not considered. ${ }^{9,10}$

The liver has a unique immunological environment comprising various immune cell types, presenting a considerable challenge for immunotherapy in HCC. The responses to immune checkpoint inhibitors (ICls) are critically shaped by the tumor microenvironment (TME). Especially, they are impeded by the activity of immunosuppressive cells, including regulatory $T$ cells, tumor-associated macrophages (TAMs), myeloid-derived suppressive cells (MDSCs), and neutrophils, which are associated with an unfavorable prognosis." Also, TAMs have central immune-regulatory roles and may limit the efficacy of immune-based therapy via crosstalk with tumor and killer cells..$^{12}$ Immune subtyping using data from The Cancer Genome Atlas describes HCC as a C4 subtype associated with an M2 macrophage enrichment. ${ }^{7,13,14}$ Single-cell RNA-sequencing analyses identified two important clusters of immune-suppressive cells in the TME of HCC. ${ }^{15}$ One corresponds to TAMs and the other is lysosome-associated membrane glycoprotein 3-positive dendritic cells (DCs). ${ }^{15}$ Another single-cell analysis of primary and early-relapse HCC samples demonstrated that macrophages are enriched in tumors compared with their levels in adjacent nontumors. ${ }^{16}$ Analyses of macrophage pro- and antiinflam- matory scores demonstrated that infiltrated macrophages have an immunosuppressive phenotype. ${ }^{16}$ Collectively, recent single-cell RNA-sequencing reports demonstrate that TAMs constitute a principal immunosuppressive population in the TME of HCC. ${ }^{15-17}$

This review focuses on the origin and functional characteristics of TAMs and their crosstalk with other cell types in the TME of HCC.

\section{IMMUNOLOGICAL HETEROGENEITY OF HCC}

$\mathrm{HCC}$ is typically characterized by the gradual dysfunction of innate-like and adaptive immune cells and an increase in the number of immune-regulatory cells in the TME. ${ }^{14}$ Recently, a trajectory from proliferative to exhausted $\mathrm{CD} 8^{+} \mathrm{T}$ cells was shown in HCC by an RNA velocity analysis. ${ }^{15}$ When T cells are exhausted, the expression of several inhibitory receptors, including PD-1, lymphocyte activation gene 3 (LAG3), T cell immunoglobulin and mucin-domain containing-3 (TIM-3), and T cell immunoreceptor with Ig and ITIM domains (TIGIT), is upregulated and the effector function is impaired by transcriptional changes mediated by TOX. ${ }^{18}$ The exhausted CD8 ${ }^{+}$ $T$ cell population is heterogeneous. Two identified subgroups are PD-1 ${ }^{1} \mathrm{TCF}^{+}$cells, capable of self-regeneration, and terminally exhausted PD-1 ${ }^{+} \mathrm{TCF}^{-}$cells. ${ }^{19-21}$ The response to antiPD-1 improves when PD-1 $1^{+} \mathrm{TCF}^{+}$cells are dominant, but not when the terminally exhausted PD-1 ${ }^{+} \mathrm{TCF} 1^{-} \mathrm{T}$ cells replace their precursors in the TME. ${ }^{19-21}$

Multiplex immunohistochemistry and gene expression assays of 919 regions of $158 \mathrm{HCC}$ tissues revealed that the immune microenvironment in $\mathrm{HCC}$ is heterogeneous and can be classified into three different subtypes: immune-high, -mid, and -low. ${ }^{22}$ These "immune classes" are related to patient survival. ${ }^{22}$ The immune-high class can be further divid-

\footnotetext{
Abbreviations:

Clec4F, C-type lectin domain family 4 member F; CSF-1, colony-stimulating factor-1; DAA, direct-acting antivirals; DCs, dendritic cells; EMT, epithelial-to-mesenchymal transition; GPIba, glycoprotein 1b alpha; HCC, hepatocellular carcinoma; HCV, hepatitis C virus; HGF, hepatocyte growth factor; HIF1a, hypoxia-inducible factor 1-alpha; ICls, immune checkpoint inhibitors; IFN-y, interferon-gamma; IL, interleukin; JAK2, Janus kinase 2; KCs, Kupffer cells; LAG3, Iymphocyte activation gene 3; MAIT, mucosalassociated invariant T cell; MDSCs, myeloid-derived suppressive cells; MIP-1a, macrophage inflammatory protein-1 alpha; MoMfs, monocyte-derived macrophages; MRS, myeloid response score; NASH, nonalcoholic steatohepatitis; NF-kB, nuclear factor-kappa B; NK, natural killer; NO, nitric oxide; ORR, objective response rate; PDL1, programmed death ligand 1; PD, programmed death; PI3KY, phosphatidylinositol 3-kinase gamma; PTEN, phosphatase and tensin homolog; RT, radiotherapy; STAT3, signal transducer and activator of transcription 3; SIRPa, signal regulatory protein alpha; SREBP1, sterol regulatory element-binding protein 1; TAMs, tumor-associated macrophages; TANs, tumor-associated neutrophils; TGF- $\beta$, transforming growth factor-beta; TIGIT, T cell immunoreceptor with Ig and ITIM domains; TIM-3, T cell immunoglobulin and mucin-domain containing-3; Tim4, T cell immunoglobulin and mucin-domain containing 4; TKI, tyrosine kinase inhibitor; TLR, toll-like receptor; TME, tumor microenvironment; TNF-a, tumor necrosis factor-alpha; TREM2, triggering receptor expressed on myeloid cells 2; VISTA, V-domain Ig-containing suppressor of $\mathrm{T}$ cell activation
} 
ed into two TME-based subclasses. The "active immune" subclass is supplemented with T cell effectors, such as interferon-gamma (IFN- $\gamma$ ) and granzyme B signatures. The "exhausted immune" subclass includes signatures of exhausted T cells, immunosuppressive TAMs, and transforming growth factor-beta (TGF- $\beta$ ) signaling. ${ }^{22}$ A subsequent broader multiomics analysis characterized "immunocompetent," "immunosuppressive," and "immunodeficient" HCC subtypes. $^{23}$ The immunocompetent subtype exhibited a robust T cell infiltration, whereas immunosuppressive cells (including regulatory T cells and TAMs) and molecules such as PD-L1 were abundant in the immunosuppressive subtype. ${ }^{23}$ Figure 1 schematically depicts the three HCC immune subtypes. ${ }^{22,23}$ Representative immunohistochemistry data using CD3 (T cell marker), CD68 (macrophage marker), and PD-L1 antibodies for three immune subtypes of HCC have been acquired (unpublished data).

Based on the immunohistochemical staining of various immune markers, a myeloid-specific prognostic signature, referred to as the myeloid response score (MRS) for HCC, was developed. ${ }^{24}$ MRS has remarkable discriminatory power in predicting survival in $\mathrm{HCC}{ }^{24} \mathrm{~A}$ higher MRS implies a stronger protumoral activity in the TME of HCC, accompanied by an increased $\mathrm{CD}^{+}{ }^{+} \mathrm{T}$ cell exhaustion. ${ }^{24}$ These findings emphasize the critical contributions of myeloid cells to immune heterogeneity in HCC. A recent study using whole-genome and RNA sequencing and cytometry by time-of-flight analysis with multiple tumor sectors demonstrated a notable im-
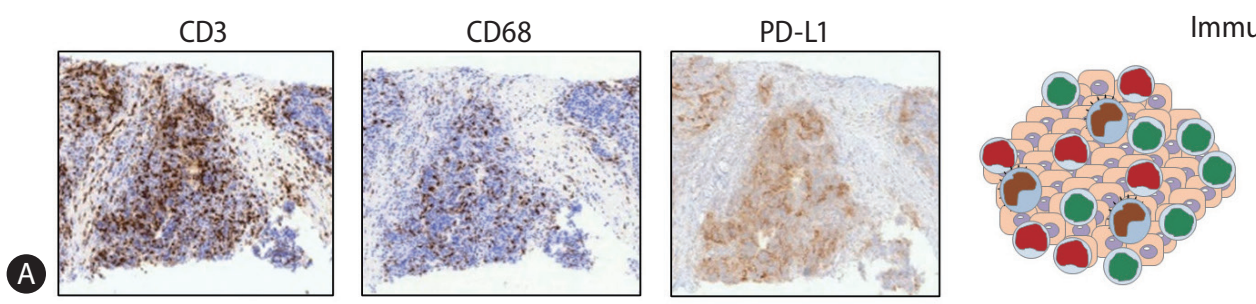

Immune checkpoint inhibitor
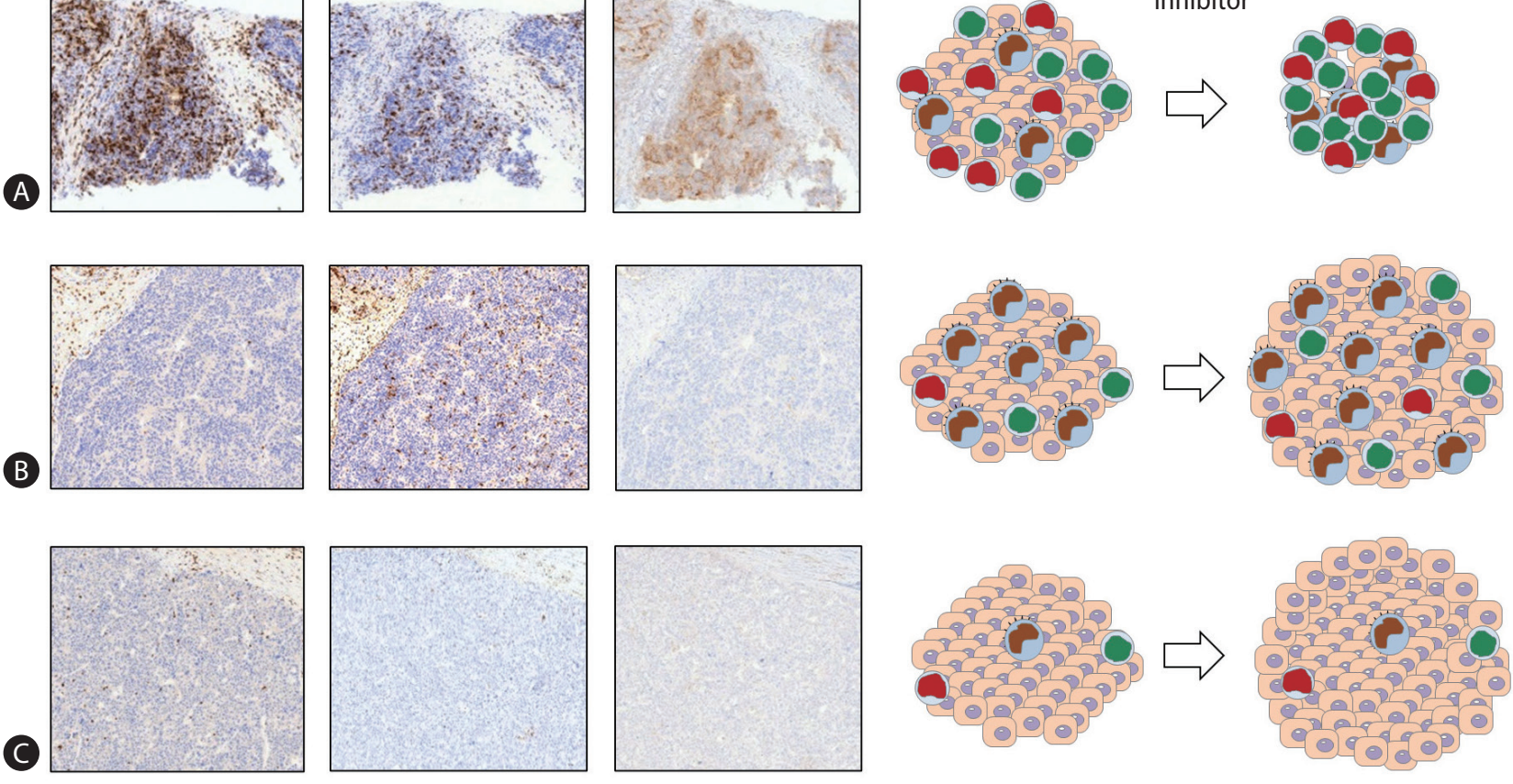

Tumor cell

TAM
$\mathrm{CD}^{+} \mathrm{T}$ cell

\section{CD4 ${ }^{+}$Th1 cell}

Figure 1. Three HCC immune subtypes. The three immune subtypes of HCC described in previous studies ${ }^{22,23}$ are schematically depicted. Representative immunohistochemistry using CD3 (T cell marker), CD68 (macrophage marker), and PD-L1 antibodies for three immune subtypes of HCC is also presented (unpublished data). (A) This subtype exhibits a robust infiltration of T cells (CTLs and Th1 cells) and M1-dominant TAM infiltration. The high expression of PD-L1 in TAMs with or without in tumor cells reflects the immunogenic nature of the tumor. This phenotype may respond well to immune checkpoint inhibitor therapies. (B) In this subtype, immunosuppressive cells including TAMs are abundantly infiltrated. However, there are few infiltrating T cells. TAMs may show PD-L1 expression, although the level of PD-L1 is not as high as that in cells with an immunocompetent phenotype. This phenotype may not respond well to immune checkpoint inhibitor therapies, and immune-based combination treatments for this subtype may be required. (C) This subtype may be referred to as the "immunodeficient" subtype. The infiltration of T cells and TAMs is poor, which may stem from poor tumor immunogenicity. This subtype may not respond to immune-based therapy unless antigen release by the locoregional or systemic therapies results in local inflammation sufficient to cause the infiltration of immune cells. PD-L1, programmed death ligand 1; TAM, tumor-associated macrophage; HCC, hepatocellular carcinoma. 
mune intratumoral heterogeneity in $\mathrm{HCC} .{ }^{25}$ Tumors with pronounced immune intratumoral heterogeneity displayed a more immunosuppressive TME associated with worse clinical outcomes. $^{25}$

Clinically, the maximal tumor diameter is the only significant pretreatment parameter for the prediction of survival outcomes after nivolumab treatment. ${ }^{26}$ The response to nivolumab differs according to tumor size in patients with $\mathrm{HCC}$, perhaps stemming from intratumoral heterogeneity in larger tumors. ${ }^{27}$ This heterogeneity may be explained by an innate or acquired resistance of tumor cells, or by the frail immune environment, and must be overcome to maximize treatment efficacy. Immune-based combination therapies with synergistic effects may be an inevitable approach. ${ }^{28} \mathrm{In}$ deed, bevacizumab plus atezolizumab, lenvatinib plus pembrolizumab, and camrelizumab plus apatinib have achieved promising ORRs in clinical trials for advanced HCC., ${ }^{1,28}$

\section{ORIGINS AND FUNCTIONS OF LIVER MACRO- PHAGES}

There is considerable heterogeneity within intrahepatic macrophage pools. Two subgroups of liver macrophages are identified depending on their origin and activity. Kupffer cells (KCs) are derived from erythromyeloid progenitor cells in the fetal yolk sac. $\mathrm{KC}$ s are liver-resident, nonmigratory macrophages capable of self-regeneration. ${ }^{29}$ They are found in the hepatic sinusoids and differ from circulating monocyte-derived macrophages (MoMfs) stemming from the bone marrow. ${ }^{30} \mathrm{KCs}$ and MoMfs have overlapping phenotypes and are challenging to differentiate in humans owing to a lack of lineage-specific markers. ${ }^{30}$ Multiple MoMfs differentiate and exhibit a phenotype that, under specific conditions, is virtually identical to that of KCs. ${ }^{31,32}$ Two markers have been proposed as candidates to distinguish MoMfs from KCs: C-type lectin domain family 4 member $F$ (Clec4F) and T cell immunoglobulin and mucin-domain containing 4 (Tim4). ${ }^{33}$ Clec4F and Tim4 are expressed in $\mathrm{KCs}$ but are not present in infiltrating MoMfs. ${ }^{33,34}$

Accounting for approximately $20 \%$ of hepatic nonparenchymal cells, KCs have a key role in host defense and coordinate the inflammatory response when they detect pathogens..$^{35}$ They are involved in phagocytosis, antigen processing and presentation, and the production of proinflammatory mediators. Initially, they produce cytokines conducive to inflammation, including tumor necrosis factor-alpha (TNF- $\alpha$ ) and interleukin (IL)-1 $1 \beta, \mathrm{IL}-6, \mathrm{IL}-12$, and IL-18. ${ }^{35}$ CCL2 is a representative chemokine produced by activated macrophages, monocytes, and DCs when they are stimulated by proinflammatory cytokines. ${ }^{36}$ In the early phase of hepatic inflammation, $\mathrm{KCs}$ produce $\mathrm{CCL} 2$ to coordinate the mobilization of circulating monocytes to the liver. ${ }^{37}$ MoMf mobilization to the liver occurs during inflammation or following the experimental depletion of KCs in a CCL2/CCR2-dependent manner. ${ }^{38}$

$\mathrm{KCs}$ can also be activated by an interplay with platelets in NASH livers. ${ }^{39}$ Hyaluronic acid on the surface of $\mathrm{KCs}$ and the glycoprotein $1 \mathrm{~b}$ alpha (GPIba) platelet receptor subunit are critical for NASH and subsequent HCC. ${ }^{39,40}$ Resident KCs decrease and are replaced by a specific set of MoMfs over time in NASH. ${ }^{41}$ One subset of recruited MoMfs in NASH is termed hepatic lipid-associated macrophages. These cells express osteopontin. ${ }^{41}$ When inflammation begins in NASH livers, KCs and recruited MoMfs differentiate into proinflammatory macrophages. ${ }^{42}$ A recent study of human NAFLD livers demonstrated that gut-derived lipopolysaccharides may increase liver damage by activating macrophages via the toll-like receptor (TLR)-4 pathway. ${ }^{43}$ Triggering receptor expressed on myeloid cells 2 (TREM2) is predominantly expressed in a subset of intrahepatic macrophages and inhibits TLR signaling. ${ }^{44}$ When chronic inflammation is not resolved, profibrogenic $\mathrm{TREM}^{+} \mathrm{CD}^{+}{ }^{+}$scar-associated macrophages differentiate from MoMfs and expand in the fibrotic liver. ${ }^{45}$

\section{ORIGINS AND FUNCTIONS OF TAMs IN HCC}

A recent cross-tissue, single-cell analysis of human macrophages demonstrated that every cancer type involves the infiltration of conserved TAM populations. ${ }^{46}$ The IL $4 I 1^{+} \mathrm{PD}$ $\mathrm{L}^{+} \mathrm{IDO}^{+}$and TREM2 $2^{+}$TAM subsets accumulate in various types of human cancers, including HCC. The cells display immunosuppressive phenotypes and promote the infiltration of regulatory T cells. ${ }^{46}$ Moreover, recent single-cell RNA-sequencing data for HCC tissues demonstrated that TAM subgroups are not associated with liver-resident $\mathrm{KCs}\left(\mathrm{MARCO}^{+}\right)$ or MDSCs $\left(\mathrm{CD}_{3} 3^{+}\right)$, suggesting that TAMs mainly originate from circulating monocytes. ${ }^{16} \mathrm{~A}$ recent report based on imaging mass cytometry of 562 highly multiplexed HCC tissue samples demonstrated that regional immunity is determined 
by resident $\mathrm{KCs}$ with a protumor function and infiltrating macrophages with an antitumor function. ${ }^{47}$ This suggests that the specific targeting of $\mathrm{KCs}$, rather than overall myeloid cell blocking, should be a novel immunotherapy for HCC.

Monocytes can be recruited by chemokines. The CCL2CCR2 signaling axis may be a significant target for monocyte recruitment in the TME of HCC. CCR2 antagonist treatment effectively impedes HCC tumor growth in different murine models. ${ }^{48}$ This therapeutic approach blocks Ly- $6 C^{\text {high }}$ inflammatory monocyte infiltration, resulting in a reduction in the number of TAMs in the TME of $\mathrm{HCC} .^{49}$ In addition, the phenotype of residual TAMs reportedly shifts to the M1 phenotype by CCR2 targeting. ${ }^{49}$ An antitumor effect of a CCL2-neutralizing antibody through a decrease in the inflammatory myeloid cell population, and the enhanced function of tumor-infiltrating $\mathrm{CD}^{+} \mathrm{T}$ cells and natural killer (NK) cells was demonstrated in a murine HCC model. ${ }^{50}$ Several phase $\mathrm{I} / \mathrm{Il}$ clinical trials using a CCR2/5 inhibitor in combination with ICls for various solid tumors are expected to provide additional insights toward improving the efficacy of $\mathrm{ICls}^{51}$

Macrophages are classified into M1 or M2 according to their phenotypes. ${ }^{52}$ Macrophage polarization is influenced by tumor stage and differs among tumors or areas within a tumor. ${ }^{34} \mathrm{HCC}$ tumor progression was once considered to be associated with a skew in the macrophage phenotype from M1 to M2 phenotypes. ${ }^{33,53,54}$ However, recent singlecell analyses have revealed coexisting $\mathrm{M} 1$ and $\mathrm{M} 2$ signatures in TAMs, indicating that the TAM phenotype may not be simply defined by using the classical M1/M2 model. ${ }^{16}$ The TME of HCC is infiltrated by PD-L1-expressing "activated" monocytes with protumoral features. ${ }^{55,56}$ Generally, PD-L1 is expressed at a higher level in macrophages/monocytes with an activated M1 phenotype. ${ }^{12}$ Therefore, TAMs in the TME of HCC cannot be defined as a pure M2 phenotype. Rather, they are composed of heterogeneous populations in terms of M1/M2 polarization. The expression of PD-L1 was reported to be higher in macrophages compared to that in cancer cells, providing a potential indicator for the response to immunotherapy in HCC. Additionally, PD-L1+ TAMs from the analyzed HCC samples did not exhibit a complete M2 polarization. ${ }^{12}$ AdditionalIy, these TAMs exhibited a high HLA-DR expression, reflecting the potential immunogenic nature of tumor cells and susceptibility to therapy designed to deplete these PD-L1-expressing TAMs. ${ }^{57,58}$

\section{CROSSTALK BETWEEN TAMS AND TUMOR CELLS IN HCC}

TAMs interact with tumor cells in various ways in HCC. Figure 2 schematically describes the routes of crosstalk between TAMs and neighboring cells in the TME of HCC. The following subsections describe the current evidence for a crosstalk between TAMs and tumor cells.

\section{Direct crosstalk}

Liver cancer stem cells are the cause of the aggressiveness and treatment resistance in $\mathrm{HCC}{ }^{59} \mathrm{CD} 24$ is preferentially expressed in a subset of liver cancer stem cells. ${ }^{60}$ Generally, CD24-expressing tumors can be protected from phagocytosis because CD24 interacts with siglec-10, an inhibitory receptor expressed by TAMs. ${ }^{61}$ Therefore, it can be inferred that CD24-expressing liver cancer stem cells can also evade macrophage phagocytosis.

Signal regulatory protein alpha (SIRPa) is an inhibitory receptor molecule expressed on macrophages. SIRPa interacts with CD47 on tumor cells. ${ }^{62}$ It is considered a key immunemodulatory checkpoint of macrophages. ${ }^{62}$ SIRPa expression in macrophages is correlated with poor survival in $\mathrm{HCC}^{63}$ In tumor cells, the CD47-SIRPa interaction acts as a protective signal to evade macrophage surveillance and phagocytic removal. ${ }^{64}$ Treatment with anti-CD47 antibodies promotes the phagocytosis of tumor cells via activated macrophages. ${ }^{65} \mathrm{An}$ ti-CD47 treatment combined with doxorubicin further enhances macrophage phagocytosis, suggesting that antiCD47 antibody treatment could be complementary to transarterial chemoembolization in $\mathrm{HCC}^{66}$

\section{Cytokines/chemokines}

CD133 ${ }^{+}$liver cancer stem cells secrete IL- $8,{ }^{67}$ which stimulates M2 polarization of TAMs to enhance the tumor's malignant potential. ${ }^{68,69}$ TAMs are a principal source of paracrine $\mathrm{IL}-6{ }^{70} \mathrm{IL}-6$ generated by TAMs stimulates tumor cells, ${ }^{71}$ resulting in the intracellular activation of the signal transducer and activator of transcription 3 (STAT3) pathway to increase the proliferation of liver cancer stem cells. ${ }^{71} \mathrm{M} 2$ polarization is reportedly stimulated by the activation of IL- $6 /$ STAT3 signaling in macrophages. ${ }^{70}$ Therefore, anti-IL- 6 treatment may have direct and indirect antitumor effects in HCC. 


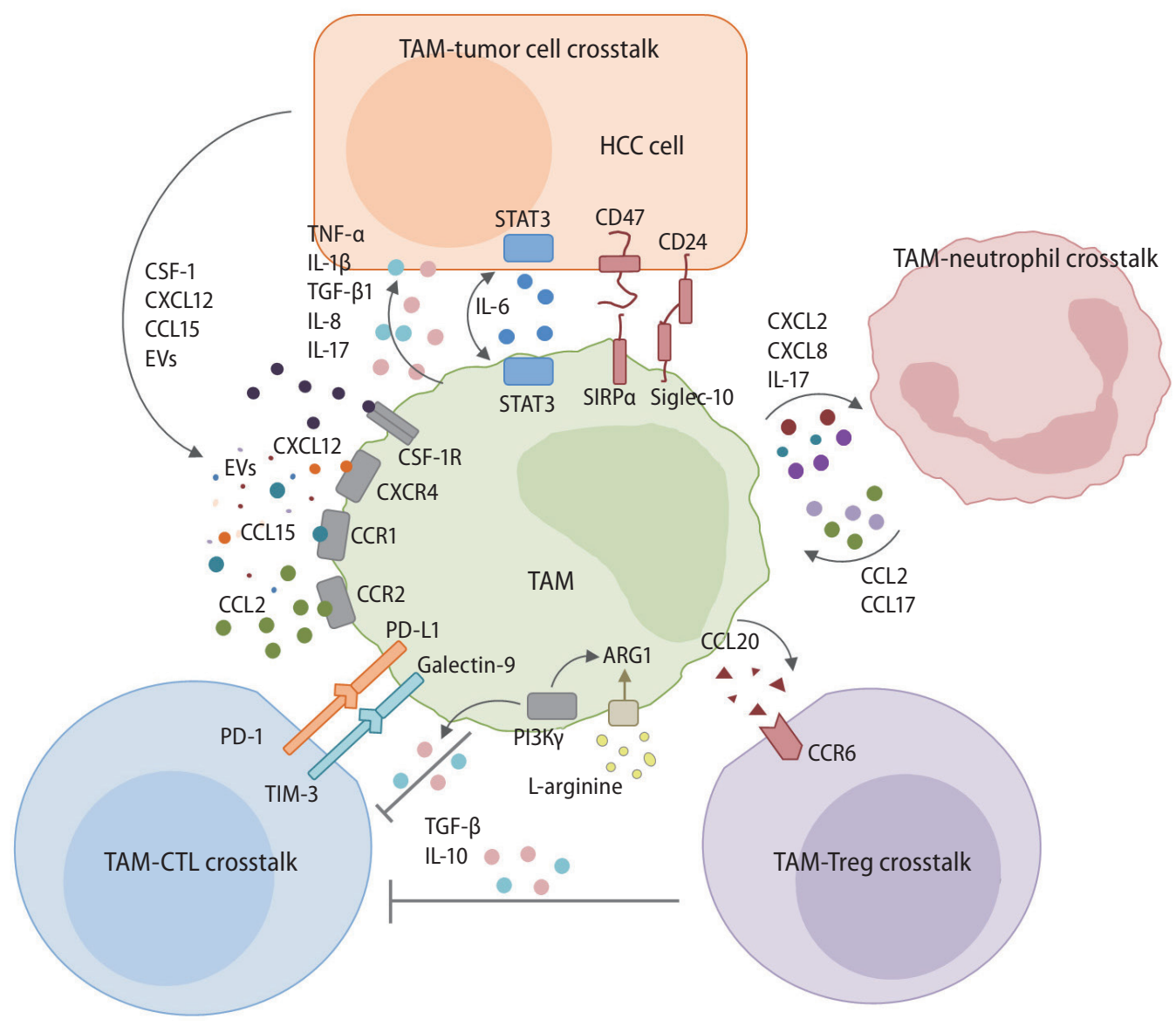

Figure 2. Crosstalk between TAMs and neighboring cells in the TME of HCC. TAMs interact with tumor cells in various ways in HCC. This figure schematically describes the crosstalk between TAMs and neighboring cells in the TME of HCC. One route is the crosstalk between TAMs and tumor cells. Various cytokines, chemokines, and extracellular vesicles are produced by tumor cells. Macrophages are recruited and differentiate into TAMs. TAMs also produce various cytokines that confer a malignant potential to tumor cells. The direct crosstalk between TAMs and HCC tumor cells is mediated by CD47/SIRPa or CD24/siglec-10 pathways. TAMs have a critical crosstalk with CTLs, resulting in the inhibition of anti-tumor activity with the involvement of the PD-1/PD-L1 or TIM-3/galectin-9 pathway. Moreover, PI3Kץ mediates the immunosuppressive activity of TAMs by enhancing arginase-1 activity and the IL-10 secretion of TAMs. L-arginine depletion by an enhanced arginase-1 activity in TAMs also causes the exhaustion of antigen-specific T cells in the TME. Regulatory T cells (Tregs) are also recruited to the TME of HCC by CCL20. CCL20 is produced by TAMs and binds to CCR6 in Tregs. Neutrophils are recruited to the TME by chemokines produced by TAMs. They also recruit TAMs by secreting CCL2 and CCL17. Collectively, TAMs usually have central immunosuppressive roles in the TME of HCC, although the phenotype of these macrophages varies significantly because of the heterogeneity of HCC. TAM, tumor-associated macrophage; HCC, hepatocellular carcinoma; CSF-1, colony-stimulating factor-1; EVs, extracellular vesicles; TNF- $\alpha$, tumor necrosis factor-alpha; IL, interleukin; TGF- $\beta$, transforming growth factor-beta; STAT3, signal transducer and activator of transcription 3; SIRPa, signal regulatory protein alpha; PD-L1, programmed death ligand 1; TIM-3, T cell immunoglobulin and mucin-domain containing-3; PI3Ky, phosphatidylinositol 3-kinase gamma; TME, tumor microenvironment.

TNF- $a$ derived from TAMs promotes cancer stemness in HCC by activating the Wnt/ $\beta$-catenin signaling pathway. ${ }^{72}$ Within a hypoxic microenvironment, the epithelial-to-mesenchymal transition (EMT) in HCC cells could be induced by IL-1 $\beta$ produced by TAMs via the hypoxia-inducible factor 1-alpha (HIF1a)/IL-1 $\beta /$ TLR4 pathway. ${ }^{73}$ Furthermore, the EMT of tumor cells may also be triggered by IL-8 secreted from TAMs via the Janus kinase 2 (JAK2)/STAT3/Snail pathway. ${ }^{7475}$ The EMT of tu- mor cells is also activated by TGF- $\beta 1$ produced by TAMs. ${ }^{76}$

Tumor cell autophagy can be induced by cytokines produced by TAMs and may also confer resistance to cytotoxic stimuli. ${ }^{77}$ Oxaliplatin cytotoxicity in SMMC-7721 and Huh-7 cell lines and HCC xenografts may be suppressed by tumor cell autophagy activated by TAMs. ${ }^{78}$ When HCC is treated with oxaliplatin, M2-TAMs produce more IL-17, promoting autophagy in cancer cells. ${ }^{79}$ The autophagy of macrophages 
themselves also has a critical impact on HCC development and progression. ${ }^{33}$ Autophagy-deficient $\mathrm{KC}$ s promote inflammation and $\mathrm{HCC}$ development by enhancing the activity of the mitochondrial reactive oxygen species/nuclear factorkappa B (NF-KB)/L-1a/ $/ 3$ signaling axis. ${ }^{80} \mathrm{~A}$ recent study using mice with a myeloid-specific knockdown of ATG5 demonstrated an increased hepatocarcinogenesis and altered antitumoral immune response compared to wild-type mice. ${ }^{81}$ Collectively, these findings suggest that various cytokines produced by TAMs critically influence tumor cells and macrophages.

CCL15 is one of the most abundantly expressed chemokines in $\mathrm{HCC}$ cells. It recruits $\mathrm{CCR}^{+}$cells to the TME of $\mathrm{HCC}^{82}$ The recruited $\mathrm{CCR} 1^{+} \mathrm{CD} 14^{+}$monocytes express significantly higher levels of immune checkpoint molecules, including PD-L1 and TIM-3. ${ }^{82}$ The activated CCL15-CCR1 axis indicates an inflammatory microenvironment infiltrated with $\mathrm{CCR}{ }^{+}$ monocytes and tumor cells with high metastatic potential and may become a target for HCC therapy. ${ }^{82}$

\section{CSF-1/CSF-1R axis}

Differentiation and functioning of macrophages can only be achieved by stimulation with colony-stimulating factor-1 (CSF-1) and its receptor, CSF-1R. Tumor cells can directly recruit TAMs via the CSF-1/CSF-1R axis. In HCC tumor cells, SLC7A11, whose expression is positively associated with worse tumor differentiation, upregulates the expression of CSF-1 and PD-L1 via the alpha-ketoglutarate-HIF1a cascade. ${ }^{83}$ SLC7A11 overexpression in tumor cells promotes TAM infiltration in the TME of HCC via the CSF-1/CSF-1R axis. ${ }^{83}$ The CSF-1 pathway is activated by miR-148b depletion in HCC cells, which promotes TAM recruitment into the TME of $\mathrm{HCC}{ }^{84} \mathrm{An}$ other microRNA, miRNA-26a, suppresses macrophage recruitment by downregulating CSF in HCC cells. ${ }^{85}$

The use of a competitive CSF-1R inhibitor substantially impedes tumor growth in murine xenograft models. TAMs in CSF-1R inhibitor-treated tumors are polarized toward an M1-like phenotype, as determined by gene expression profiling. ${ }^{86}$ In mouse models of HCC, two possible consequences of blocking the CSF-1/CSF-1R signaling pathway were identified: TAM reprogramming from the M2 phenotype to the M1, and the suppression of PD-L1 expression, potentiating the response to PD-1/PD-L1 therapy. ${ }^{86,87}$

\section{Crosstalk by extracellular vesicles}

Exosomes from TAMs may promote tumor growth and cancer stemness in HCC. A recent study showed that the exosome-mediated transfer of functional CD11b/CD18 protein from TAMs to tumor cells enhances the migratory potential of HCC cells. ${ }^{53}$ miR-125a/b in exosomes inhibited the activity of liver cancer stem cells by targeting CD90, although TAMderived exosomes had decreased levels of miR-125a/b to increase tumor cell stemness. ${ }^{88}$ Conversely, emerging evidence indicates that tumor cell-derived exosomes or exosomal miRNAs contribute to HCC progression by enhancing macrophage infiltration or activation. Endoplasmic reticulum stress causes tumor cells to secrete exosomal miR-23a-3p. ${ }^{89}$ The exosomal transfer of miR-23a activates the phosphatase and tensin homolog (PTEN)-AKT pathway and increases PD-L1 expression in macrophages. ${ }^{89}$ Exosomes of tumor cells are also enriched in miR-146a-5p, which results in the M2-polarization of TAMs and may cause T cell exhaustion. ${ }^{90}$

\section{CROSSTALK BETWEENTAMS AND NK CELLS IN HCC}

In the TME of HCC, NK cells are less abundant and dysfunctional. ${ }^{59} \mathrm{~A}$ major mechanism regulating NK cell function is the crosstalk between various immune cell populations, such as TAMs, in the TME of HCC. ${ }^{91}$ TAMs indirectly inhibit NK cells via cytokines, such as IL-10 and TGF- $\beta .^{91}$ Additionally, TAMs express CD48 in the TME of $\mathrm{HCC}$ and may directly interact with 2B4 on NK cells, resulting in NK cell dysfunction. ${ }^{92}$ Conversely, M1 macrophages may increase the total number of activated intrahepatic NK cells in chronic liver diseases. ${ }^{93}$ This suggests that when TAMs are repolarized to the M1 phenotype, they may stimulate NK cells to kill tumor cells.

\section{CROSSTALK BETWEEN TAMS AND T CELLS IN HCC}

TAMs can regulate the tumor cell killing ability of T and NK cells. This TAM-mediated suppression, rather than tumor cellmediated suppression, may be the principal mechanism underlying tumor-specific T cell dysfunction in the TME of HCC. A decade ago, two studies independently demonstrated that macrophages are the principal nonparenchymal cells in the TME that express PD-L1 in HCC. ${ }^{94,95}$ These findings were con- 
firmed in several subsequent studies. A recent spatial analysis revealed a positive correlation between the number of infiltrating PD- $1^{\text {high }} \mathrm{TIM3}^{+} \mathrm{CD}^{+} \mathrm{T}$ cells and the number of PD- $\mathrm{L1}^{+}$ TAMs and a lack of correlation with the number of PD- $\mathrm{L1}^{+} \mathrm{tu}-$ mor cells. ${ }^{96}$ Likewise, our group obtained similar results showing that PD- $\mathrm{L1}^{+} \mathrm{TAMs}$, but not PD-L1 ${ }^{+}$tumor cells, are located near infiltrating $\mathrm{CD} 8^{+} \mathrm{T}$ cell subsets. ${ }^{96} \mathrm{~A}$ recent study confirmed that PD-L1 on TAMs suppresses tumor-specific T cell responses in $\mathrm{HCC}{ }^{97}$ Using a myeloid-specific pdl1-knockout mouse model, the authors demonstrated that PD-L1 on TAMs directly suppresses intratumoral $\mathrm{CD} 8^{+} \mathrm{T}$ cells. ${ }^{97}$ They also found that tumor-derived Sonic hedgehog causes the upregulation of PD-L1 in TAMs. ${ }^{97}$

Arginine metabolism is critically related to TAM polarization. ${ }^{98}$ The production of nitric oxide (NO) from arginine in M1 macrophages causes cytolysis of tumor cells, although M2 macrophages have increased enzymatic activities of arginase with a reduction in arginine levels and NO production. ${ }^{98}$ Arginine is a critical amino acid involved in antitumor immunity involving the activation of T cells via T cell receptor upregulation. ${ }^{99}$ Arginase produced by TAMs and MDSCs depletes extracellular arginine and suppresses $T$ cell activation. ${ }^{100}$ Supplementation with arginine normalizes $T$ cell metabolism from glycolysis to oxidative phosphorylation and promotes survival and antitumor activity, suggesting that arginine deficiency by $\mathrm{M} 2$ macrophages is a target for immunotherapy in HCC. ${ }^{101}$

Phosphatidylinositol 3-kinase gamma (PI3KY) stimulates the activation of the "immunosuppressive program" in TAMs. ${ }^{102}$ Macrophage PI3KY suppresses T cell activation, while the lack of its activity in TAMs reduces the production of immunosuppressive molecules, including IL-10 and arginase, and enhances antitumor T cell responses. ${ }^{102}$ Another study demonstrated the potential value of targeting myeloid-intrinsic PI3KY to overcome ICI resistance. ${ }^{103}$ These critical roles of PI3KY in TAMs need to be confirmed in HCC.

In chronic hepatitis $\mathrm{C}$ virus (HCV) infection, rapid viral eradication by direct-acting antivirals (DAAs) changes the phenotype of infected hepatocytes and intrahepatic monocytes/ macrophages while contributing to HCC. ${ }^{20,104,105}$ The inflammatory activity of intrahepatic macrophages, which is closely associated with mucosal-associated invariant T (MAIT) cell activity, is markedly attenuated after rapid viral clearance by DAAs. ${ }^{106}$ MAIT cells are activated by IL-12, IL-15, and IL-18, which are usually produced by activated macrophages/ monocytes. ${ }^{107}$ Usually, DAA therapy causes an immediate reduction in IL-18 levels in chronic HCV infection, resulting in a rapid decrease in intrahepatic inflammation and MAIT cell cytotoxicity. ${ }^{108,109}$ The decreased cytotoxicity of MAIT cells with the reduction in proinflammatory cytokine production by macrophages after DAA treatment may be related to HCC recurrence after DAA-mediated HCV clearance.

\section{CROSSTALK BETWEEN TAMS AND REGULA- TORY T CELLS IN HCC}

Regulatory $\mathrm{T}$ cells are a major immunosuppressive cell population and have various effects on tumor progression. ${ }^{110}$ A recent study in which the CIBERSORT algorithm was used to estimate the relative frequencies of 22 subsets of tumorinfiltrating immune cells in 1,090 HCC cases revealed four tumor clusters."11 Tumors with increased regulatory T cells and decreased M1 macrophages were associated with a worse prognosis. ${ }^{111}$ However, M2 TAMs, and not M1 macrophages, tend to promote the recruitment of regulatory $T$ cells to the TME. The infiltration of TREM-1 $1^{+}$TAMs in the TME of HCC is critical for resistance to anti-PD-L1 within the hypoxic TME by the recruitment of $\mathrm{CCR}^{+}{ }^{+}$Foxp $^{+}{ }^{+}$regulatory $\mathrm{T}$ cells via CCL20 production. ${ }^{112}$ The recruited or induced regulatory $T$ cells can further enhance the immunosuppressive properties of TAMs. Regulatory T cells promote the sterol regulatory elementbinding protein 1 (SREBP1)-mediated metabolic processes of M2 TAMs by repressing the production of IFN- $\gamma$ by $C D 8^{+} T$ cells. ${ }^{113}$ Therefore, regulatory T cells indirectly sustain M2 TAM survival, forming a positive feedback pool. ${ }^{113}$

\section{CROSSTALK BETWEEN TAMS AND T FOLLICU- LAR HELPER CELLS/PLASMA CELLS IN HCC}

HCC is a typical example of inflammation-associated cancer. ${ }^{114}$ TAMs also cause cancer-related inflammation, resulting in the generation of an inflammatory helper T cell subset, such as T follicular helper cells, in the TME of HCC."15 TLR4-induced monocyte activation is critical for the generation of IL21 $1^{+} \mathrm{T}$ follicular helper cells with a CXCR5 ${ }^{-}$PD-1 ${ }^{-} \mathrm{BTLA}^{-} \mathrm{CD}$ $69^{\text {high }}$ tissue-resident phenotype in the TME of HCC. These cells induce plasma cells, leading to the ideal conditions for M2 TAM induction and cancer progression. ${ }^{115}$ 
Liver IgA $\mathrm{A}^{+}$plasma cells directly suppress cytotoxic $\mathrm{T}$ cell activation in vitro and in vivo, inducing their exhaustion. ${ }^{116}$ Moreover, recent data have demonstrated that IgA complexstimulated monocytes/macrophages also show an inflammatory phenotype and express higher PD-L1 levels in the TME of HCC. ${ }^{117}$ These IgA ${ }^{+}$TAMs may be a target for improving the efficacy of immune-based therapy in HCC.

\section{CROSSTALK BETWEEN TAMS AND NEUTRO- PHILS IN HCC}

Tumor-associated neutrophils (TANs) might support the progression of tumors by hampering antitumor immunity. ${ }^{118}$ Monocyte-derived CXCL2 and CXCL8 play critical roles in recruiting neutrophils into the TME of HCC. ${ }^{119} \mathrm{~A}$ recent study demonstrated that the glycolytic switch in monocytes mediates the upregulation of $\mathrm{CXCL2}$ and CXCL8 via the 6-phosphofructo-2-kinase/fructose-2,6-biphosphatase 3-NF-KB pathway. ${ }^{119}$ Moreover, the proinflam- matory cytokine IL-17 contributes to TAN recruitment to the TME. ${ }^{118}$ Neutrophils also have critical functions in the recruitment of macrophages and regulatory $T$ cells to the TME of HCC via the production of cytokines or chemokines. ${ }^{120}$ Besides, a positive correlation has been observed between the extent of TAN infiltration and angiogenesis at the tumor-invading margin in patients with HCC. ${ }^{121}$ CCL2 and CCL17 are the chemokines robustly produced by TANs and peripheral blood neutrophils, which strongly recruit macrophages into the TME of HCC..$^{120}$ Therefore, the infiltration of TANs is a poor prognostic factor, because they further recruit TAMs and block tumor-specific immunity in HCC.

\section{MODULATION OF THE TAM POPULATION BY CURRENT HCC THERAPIES}

Although many innovative approaches to modulate TAMs are now being developed, no specific methods targeting

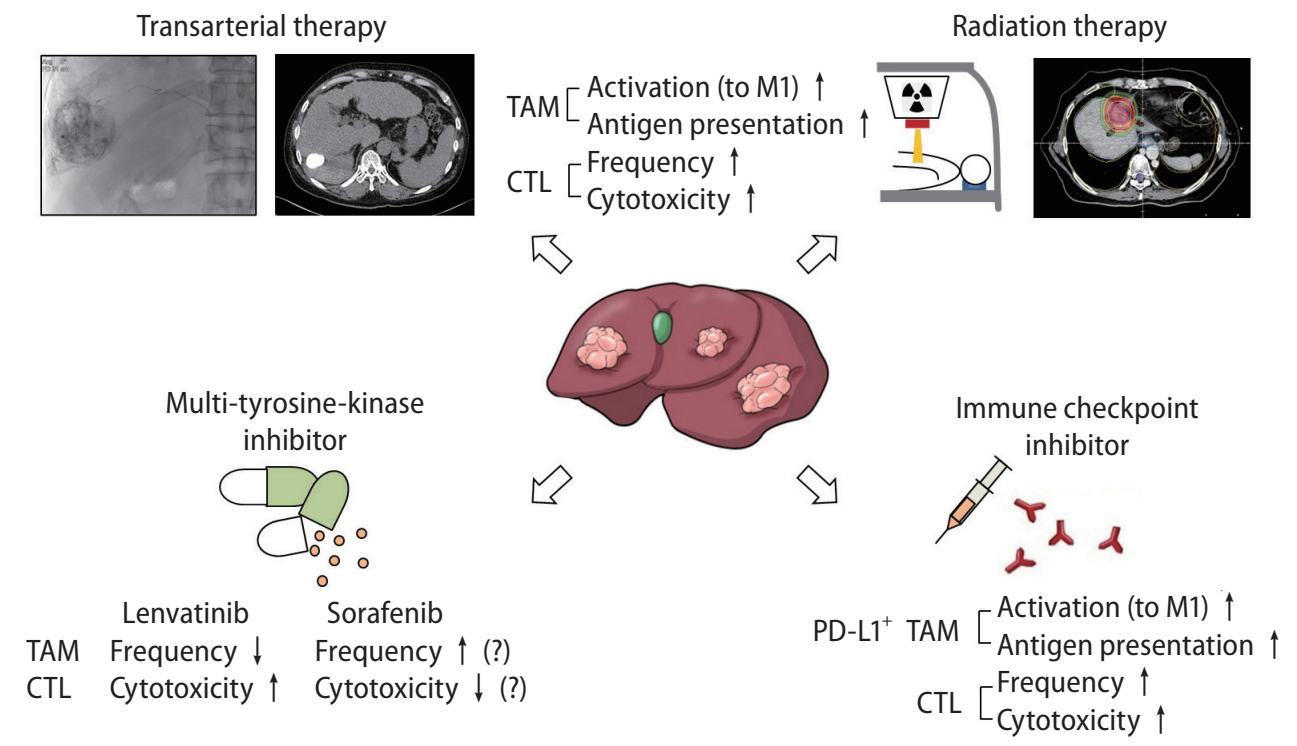

Figure 3. Modulation of the TAM population in the TME of HCC by current standard therapies. This figure schematically describes the various HCC treatments and their effects on TAMs. Transarterial therapy, such as transarterial chemoembolization or transarterial radioembolization and radiation therapy, may activate TAMs in the TME of HCC to exhibit an M1-like phenotype and enhance their antigen presentation. In response to TAM activation, the number and cytolytic function of infiltrated CTLs may be increased by these therapeutic modalities. One of the multi-tyrosine kinase inhibitors for HCC, lenvatinib, is known to have robust immune-modulating effects for HCC. Lenvatinib decreases the number of infiltrated TAMs and activates CTLs in the TME. Conversely, intratumoral hypoxia caused by sorafenib, another multi-tyrosine kinase inhibitor used for more than a decade, may increase the number of TAMs in the TME of HCC, resulting in decreased CTL activity. In immunogenic HCC, PD-L1 is preferentially expressed in TAMs, rather than in tumor cells. ICI treatment in HCC activates these PD-L1+ TAMs, resulting in enhanced CTL activity. TAM, tumor-associated macrophage; PD-L1, programmed death ligand 1; HCC, hepatocellular carcinoma; TME, tumor microenvironment; ICl, immune checkpoint inhibitor. 
TAMs in HCC are currently being clinically implemented. The following sections focus on the effects of current HCC therapies on TAMs in the TME. Figure 3 schematically describes various HCC treatments and their immune-modulating effects.

\section{Locoregional treatments/radiotherapy (RT)}

There is strong evidence that the combinatorial approach of locoregional therapies with $\mathrm{ICls}$ enhances the immunemodulatory effect of locoregional therapies in HCC. ${ }^{122}$ Transcriptomic analysis and the deep immunophenotyping of tissues from patients undergoing $\mathrm{Y}^{90}$-radioembolization demonstrated strong immune activation in the TME and peripheral blood of patients with prolonged responses. ${ }^{123}$ Interestingly, a significantly higher proportion of peripheral CD14 ${ }^{+} \mathrm{HLADR}^{+}$monocytes was observed 3 months after therapy in patients with sustained responses, suggesting that the number of antigen-presenting cells is higher in these patients. ${ }^{123}$ Interestingly, a recent study demonstrated the local immune-boosting effects (CTL infiltration with enhanced cytotoxicity) of transarterial chemoembolization. ${ }^{124}$ Future studies should reveal the precise effects of locoregional treatments, such as transarterial chemoembolization, transarterial radioembolization, radiofrequency ablation, and hepatic arterial infusion chemotherapy, on TAMs in the TME of HCC.

RT has local immune-modulatory effects in HCC. Some studies have reported that irradiation hinders tumor growth and triggers the ongoing mobilization of $\mathrm{F} 4 / 80^{+} \mathrm{CD} 68^{+}$macrophages to irradiated tumors. ${ }^{125}$ This stimulates TNF- $a$ and IL-6 production and an inflammatory response. ${ }^{125}$ In murine models, lung metastasis was reportedly prevented and survival improved when irradiation was delivered with intravenously administered recombinant macrophage inflammatory protein-1 alpha (MIP-1a). ${ }^{126}$ Further research is required to determine the effect of RT on TAMs in the TME.

The synergistic effects of RT and ICls are highlighted by numerous preclinical studies. Many ongoing clinical trials are testing the efficacy of this combined approach. ${ }^{127}$ The abscopal effect, which describes the regression of tumors outside the RT field, may be boosted by the combined use of ICls. ${ }^{128} \mathrm{~A}$ recent study using a syngeneic murine model of HCC demonstrated potential abscopal effects with the increased infiltration of CTLs in both irradiated and nonirradiated tumors. ${ }^{128}$ The RT-ICl combination is also identified as a potential HCC treatment based on an observed correlation between soluble PD-L1 levels after RT and patient prognosis. ${ }^{129}$

\section{Multi-TKIs}

For patients with stage $\mathrm{C}$ or $\mathrm{B} B C L C$ who are not suitable for local or surgical treatment, systemic therapies are recommended as a first-line treatment. ${ }^{1}$ The recent randomized phase 3 trial REFLECT demonstrated that lenvatinib is noninferior to sorafenib in overall survival in treatment-naïve unresectable HCC. ${ }^{130,131}$ Additionally, lenvatinib had better progression-free survival compared to sorafenib as a salvage therapy for transarterial treatment. ${ }^{132}$ This result may be due to the immune-modulatory effects of lenvatinib. ${ }^{57}$ The immune-regulatory activity of lenvatinib is an important determinant of its antitumor effect. This activity is mediated by a reduction in TAMs and an increase in intratumoral $\mathrm{CD}^{+} \mathrm{T}$ cells. ${ }^{133}$ Lenvatinib also improves the therapeutic impact of ICls by a localized reduction in TAMs. ${ }^{134}$ PD-L1-expressing macrophage infiltration was recently demonstrated to be a potential predictor of the response to lenvatinib in unresectable HCC. ${ }^{57}$ PD-L1 ${ }^{+}$TAMs may represent tumor immunogenicity and may be targeted by ICls and lenvatinib. ${ }^{57}$

Considerable resistance to sorafenib is afforded by TAMs with an $\mathrm{M} 2$ phenotype via the production of hepatocyte growth factor (HGF) and activation of HGF/c-Met, mitogenactivated protein kinase/extracellular signal-regulated kinase $1 / 2$, and PI3K/AKT pathways in tumor cells. ${ }^{135}$ In turn, this exacerbates the infiltration of M2-TAMs and generates a positive feedback loop. ${ }^{135}$ The number of $\mathrm{CCL}^{+}$or $\mathrm{CCL}^{+} 7^{+}$TANs correlates with tumor development, progression, and sorafenib resistance, as mediated by TAMs and regulatory $T$ cell recruitment by TANs in HCC. ${ }^{120}$ As previously mentioned, monocyte/macrophage mobilization and TAM M2 polarization depend on the CCL2/CCR2 pathway in $\mathrm{HCC}^{49}$ Interestingly, blocking this pathway with a specific chemical inhibitor can potentiate the effects of sorafenib by activating the antitumor activity of CTLs. ${ }^{48}$ CXCR4 and its ligand CXCL12 are critical mediators between TAMs and tumor cells in various cancer types. ${ }^{98}$ Increased hypoxia after sorafenib treatment results in the increased accumulation of M2 TAMs and regulatory T cells, which is partly mediated by CXCR4. ${ }^{136,137}$ In a murine HCC model, anti-PD-1 immunotherapy was effective only when administered alongside CXCR4 inhibitors when intratumoral hypoxia was caused by sorafenib. ${ }^{136}$ 
Regorafenib and cabozantinib were recently approved as second-line treatments for unresectable HCC. A study recently demonstrated that regorafenib also enhances antitumor immunity by reversing the M2 polarization of TAMs. ${ }^{138}$ This provides a theoretical background supporting the use of the regorafenib and $\mathrm{ICl}$ combination treatment for HCC. ${ }^{139}$ However, for cabozantinib, the combined administration of anti-PD-L1 did not exert synergistic effects in mouse models. ${ }^{140}$ The future discovery of novel therapeutic combinations of TKIs and ICls is expected to improve patient outcomes by regulating the TAM population in the TME of HCC.

\section{Immune-based therapy}

Clinical outcomes in HCC have been significantly improved by ICls. However, the monotherapy has not elicited a response in a large proportion of cases owing to TME heterogeneity in HCC, as mentioned in previous sections. In an analysis of the single-cell landscape of HCC in response to immunotherapy, an increase in tumor heterogeneity was strongly linked to patient survival. ${ }^{141}$

As mentioned earlier, compared to M2 macrophages, M1 macrophages display an elevated expression of PD-L1/HLA$\mathrm{DR}^{52,142,143} \mathrm{CD}^{+} 8^{+} \mathrm{CD} 11 \mathrm{~b}^{+}$(M1) macrophages create an antigen-presenting niche for the differentiation of stem-like, tumor-specific CD8 ${ }^{+} \mathrm{T}$ cells, which is necessary to sustain the $\mathrm{CD}^{+} \mathrm{T}$ cell response in human cancers. ${ }^{144}$ The expression of PD-L1 in macrophages may act as a marker for an anti-PD-1/ $\mathrm{PD}-\mathrm{L} 1$ response in $\mathrm{HCC}$. The enrichment of $\mathrm{PD}-\mathrm{L}^{+}$macrophages in the TME is associated with an activated immunity in TME with a considerable $\mathrm{CD} 8^{+} \mathrm{T}$ cell infiltration and immune-related gene expression, indicating that the tumor may be responsive to immune-based therapy. ${ }^{12,57,110}$ TAM activity in HCC is also regulated by the immune checkpoint molecule TIM-3, which is highly expressed on the surface of macrophages and activated by TGF- $\beta$ in the TME. ${ }^{145}$ Other checkpoint ligands are also expressed on TAMs, including PD-L2 and B7-H4, galectin-9, and V-domain Ig-containing suppressor of T cell activation (VISTA) ${ }^{145,146}$ Collectively, TAMs express many checkpoint molecules in the TME of HCC and may be targeted by immune-based therapies.

There are several putative ways to directly deplete TAMs in the TME of HCC. In mouse models of HCC, the proportion of TAMs decreased by the injection of nanoliposome-loaded C6-ceremide, stimulating $\mathrm{CD}^{+} \mathrm{T}$ cells to exert an antitumor immune response. ${ }^{147}$ In a murine Hepa1-6 syngeneic tumor model, the number of M2-like TAMs decreased to some extent by the administration of liposome-encapsulated clodronate, leading to a decrease in tumor size, with no impact on the number of M1-like TAMs. ${ }^{148}$ Zoledronate is a third-generation nitrogen-containing bisphosphonate with selective cytotoxicity toward matrix metalloproteinase-9-expressing TAMs and with the ability to impair the differentiation of monocytes into TAMs. ${ }^{110}$ Zoledronate treatment enhanced the effects of transarterial chemoembolization by inhibiting TAM infiltration in HCC rat models. ${ }^{149}$ However, there is a concern that the general depletion of macrophages in the liver causes a loss of tissueresident macrophages mediating immune homeostasis and bacterial clearance. ${ }^{110}$

\section{CONCLUSIONS AND FUTURE DIRECTIONS}

Various clinical trials and real-world data for HCC indicate that immune-based therapy achieves encouraging clinical responses with manageable toxicity profiles. To maximize the therapeutic efficacy of immune-based therapies, TAMs in the TME of HCC are principal targets, because these cells have various crosstalk routes between tumor and other immune cells, resulting in more aggressive tumors unresponsive to treatments. Future HCC immunotherapy strategies should identify new combination approaches using current or potential treatment options targeting TAMs in the TME of HCC for optimal antitumor efficacy.

\section{Acknowledgements}

This work was supported by the financial support of the Catholic Medical Center Research Foundation in the program year of 2020. This work was also supported by the National Research Foundation of Korea (NRF) grant funded by the Korea government (MSIT) (2021R1C1C1005844). This work was also partly supported by a Young Medical Scientist Research Grant through the Daewoong Foundation (DY20204P).

\section{Conflicts of Interest}

The author has no conflicts to disclose. 


\section{REFERENCES}

1. Llovet JM, Kelley RK, Villanueva A, Singal AG, Pikarsky E, Roayaie $S$, et al. Hepatocellular carcinoma. Nat Rev Dis Primers 2021;7:6.

2. Chon YE, Jeong SW, Jun DW. Hepatocellular carcinoma statistics in South Korea. Clin Mol Hepatol 2021;27:512-514.

3. Sohn W, Lee HW, Lee S, Lim JH, Lee MW, Park CH, et al. Obesity and the risk of primary liver cancer: a systematic review and meta-analysis. Clin Mol Hepatol 2021;27:157-174.

4. Ogasawara S, Ooka Y, Koroki K, Maruta S, Kanzaki H, Kanayama $\mathrm{K}$, et al. Switching to systemic therapy after locoregional treatment failure: definition and best timing. Clin Mol Hepatol 2020;26:155-162.

5. Galle PR, Finn RS, Qin S, Ikeda M, Zhu AX, Kim TY, et al. Patientreported outcomes with atezolizumab plus bevacizumab versus sorafenib in patients with unresectable hepatocellular carcinoma (IMbrave150): an open-label, randomised, phase 3 trial. Lancet Oncol 2021;22:991-1001.

6. Finn RS, Qin S, lkeda M, Galle PR, Ducreux M, Kim TY, et al. Atezolizumab plus bevacizumab in unresectable hepatocellular carcinoma. N Engl J Med 2020;382:1894-1905.

7. Hilmi M, Neuzillet C, Calderaro J, Lafdil F, Pawlotsky JM, Rousseau B. Angiogenesis and immune checkpoint inhibitors as therapies for hepatocellular carcinoma: current knowledge and future research directions. J Immunother Cancer 2019;7:333.

8. Kudo M, Matilla A, Santoro A, Melero I, Gracián AC, AcostaRivera M, et al. CheckMate 040 cohort 5: a phase I/II study of nivolumab in patients with advanced hepatocellular carcinoma and Child-Pugh B cirrhosis. J Hepatol 2021;75:600-609.

9. El-Khoueiry AB, Sangro B, Yau T, Crocenzi TS, Kudo M, Hsu C, et al. Nivolumab in patients with advanced hepatocellular carcinoma (CheckMate 040): an open-label, non-comparative, phase $1 / 2$ dose escalation and expansion trial. Lancet 2017;389:2492-2502.

10. Sangro B, Melero I, Wadhawan S, Finn RS, Abou-Alfa GK, Cheng $\mathrm{AL}$, et al. Association of inflammatory biomarkers with clinical outcomes in nivolumab-treated patients with advanced hepatocellular carcinoma. J Hepatol 2020;73:1460-1469.

11. Zhou D, Luan J, Huang C, Li J. Tumor-associated macrophages in hepatocellular carcinoma: friend or foe? Gut Liver 2021;15:500-516.

12. Park DJ, Sung PS, Lee GW, Cho S, Kim SM, Kang BY, et al. Preferential expression of programmed death ligand 1 protein in tumor-associated macrophages and its potential role in immunotherapy for hepatocellular carcinoma. Int J Mol Sci 2021;22:4710.

13. Thorsson V, Gibbs DL, Brown SD, Wolf D, Bortone DS, Ou Yang $\mathrm{TH}$, et al. The immune landscape of cancer. Immunity 2018;48:812-830.e14.

14. Cancer Genome Atlas Research Network. Comprehensive and integrative genomic characterization of hepatocellular carcinoma. Cell 2017;169:1327-1341.e23.

15. Zhang Q, He Y, Luo N, Patel SJ, Han Y, Gao R, et al. Landscape and dynamics of single immune cells in hepatocellular carcinoma. Cell 2019;179:829-845.e20.

16. Sun Y, Wu L, Zhong Y, Zhou K, Hou Y, Wang Z, et al. Single-cell landscape of the ecosystem in early-relapse hepatocellular carcinoma. Cell 2021;184:404-421.e16.

17. Ho DW, Tsui YM, Chan LK, Sze KM, Zhang X, Cheu JW, et al. Single-cell RNA sequencing shows the immunosuppressive landscape and tumor heterogeneity of HBV-associated hepatocellular carcinoma. Nat Commun 2021;12:3684.

18. Wang X, He Q, Shen H, Xia A, Tian W, Yu W, et al. TOX promotes the exhaustion of antitumor $\mathrm{CD}^{+} \mathrm{T}$ cells by preventing PD1 degradation in hepatocellular carcinoma. J Hepatol 2019;71:731-741.

19. Siddiqui I, Schaeuble K, Chennupati V, Fuertes Marraco SA, Calderon-Copete S, Pais Ferreira D, et al. Intratumoral Tcf1 $1^{+} \mathrm{PD}$ $1^{+} \mathrm{CD} 8^{+} \mathrm{T}$ cells with stem-like properties promote tumor control in response to vaccination and checkpoint blockade immunotherapy. Immunity 2019;50:195-211.e10.

20. Sung PS, Shin EC. Immunological mechanisms for hepatocellular carcinoma risk after direct-acting antiviral treatment of hepatitis C virus infection. J Clin Med 2021;10:221.

21. Kim HD, Song GW, Park S, Jung MK, Kim MH, Kang HJ, et al. association between expression level of PD1 by tumor-infiltrating $\mathrm{CD}^{+} \mathrm{T}$ cells and features of hepatocellular carcinoma. Gastroenterology 2018;155:1936-1950.e17.

22. Kurebayashi Y, Ojima H, Tsujikawa H, Kubota N, Maehara J, Abe $Y$, et al. Landscape of immune microenvironment in hepatocellular carcinoma and its additional impact on histological and molecular classification. Hepatology 2018;68:1025-1041.

23. Zhang Q, Lou Y, Yang J, Wang J, Feng J, Zhao Y, et al. Integrated multiomic analysis reveals comprehensive tumour heterogeneity and novel immunophenotypic classification in hepatocellular carcinomas. Gut 2019;68:2019-2031.

24. Wu C, Lin J, Weng Y, Zeng DN, Xu J, Luo S, et al. Myeloid signature reveals immune contexture and predicts the prognosis of 
hepatocellular carcinoma. J Clin Invest 2020;130:4679-4693.

25. Nguyen PHD, Ma S, Phua CZJ, Kaya NA, Lai HLH, Lim CJ, et al. Intratumoural immune heterogeneity as a hallmark of tumour evolution and progression in hepatocellular carcinoma. Nat Commun 2021;12:227.

26. Sung PS, Jang JW, Lee J, Lee SK, Lee HL, Yang H, et al. Realworld outcomes of nivolumab in patients with unresectable hepatocellular carcinoma in an endemic area of hepatitis B virus infection. Front Oncol 2020;10:1043.

27. Yang H, Sung PS, Lee J, Yoon SK, Jung ES, Park CS, et al. Heterogenous responses to nivolumab in a single metastatic nodule in hepatocellular carcinoma: role of salvage surgery. Hepatobiliary Surg Nutr 2019;8:569-571.

28. Cheng AL, Hsu C, Chan SL, Choo SP, Kudo M. Challenges of combination therapy with immune checkpoint inhibitors for hepatocellular carcinoma. J Hepatol 2020;72:307-319.

29. Gomez Perdiguero E, Klapproth K, Schulz C, Busch K, Azzoni $\mathrm{E}$, Crozet $\mathrm{L}$, et al. Tissue-resident macrophages originate from yolk-sac-derived erythro-myeloid progenitors. Nature 2015;518:547-551.

30. Tacke F, Zimmermann HW. Macrophage heterogeneity in liver injury and fibrosis. J Hepatol 2014;60:1090-1096.

31. Scott CL, Zheng F, De Baetselier P, Martens L, Saeys Y, De Prijck $S$, et al. Bone marrow-derived monocytes give rise to selfrenewing and fully differentiated Kupffer cells. Nat Commun 2016;7:10321.

32. Beattie L, Sawtell A, Mann J, Frame TCM, Teal B, de Labastida Rivera $F$, et al. Bone marrow-derived and resident liver macrophages display unique transcriptomic signatures but similar biological functions. J Hepatol 2016;65:758-768.

33. Huang Y, Ge W, Zhou J, Gao B, Qian X, Wang W. The role of tumor associated macrophages in hepatocellular carcinoma. J Cancer 2021;12:1284-1294.

34. Yu SJ, Greten TF. Deciphering and reversing immunosuppressive cells in the treatment of hepatocellular carcinoma. J Liver Cancer 2020;20:1-16.

35. Ruf B, Heinrich B, Greten TF. Immunobiology and immunotherapy of HCC: spotlight on innate and innate-like immune cells. Cell Mol Immunol 2021;18:112-127.

36. Zhou J, Tang Z, Gao S, Li C, Feng Y, Zhou X. Tumor-associated macrophages: recent insights and therapies. Front Oncol 2020;10:188.

37. Heymann F, Peusquens J, Ludwig-Portugall I, Kohlhepp M, Ergen $C$, Niemietz $P$, et al. Liver inflammation abrogates immunological tolerance induced by Kupffer cells. Hepatology
2015;62:279-291.

38. Mossanen JC, Krenkel O, Ergen C, Govaere O, Liepelt A, Puengel $\mathrm{T}$, et al. Chemokine ( $\mathrm{C}-\mathrm{C}$ motif) receptor 2-positive monocytes aggravate the early phase of acetaminophen-induced acute liver injury. Hepatology 2016;64:1667-1682.

39. Malehmir M, Pfister D, Gallage S, Szydlowska M, Inverso D, Kotsiliti E, et al. Platelet GPlba is a mediator and potential interventional target for NASH and subsequent liver cancer. Nat Med 2019;25:641-655.

40. Diggs LP, Greten TF. The effects of platelet accumulation in fatty liver disease. Nat Rev Gastroenterol Hepatol 2019;16:393394.

41. Remmerie A, Martens L, Thoné T, Castoldi A, Seurinck R, Pavie $B$, et al. Osteopontin expression identifies a subset of recruited macrophages distinct from kupffer cells in the fatty liver. Immunity 2020;53:641-657.e14.

42. Kazankov K, Jørgensen SMD, Thomsen KL, Møller HJ, Vilstrup H, George J, et al. The role of macrophages in nonalcoholic fatty liver disease and nonalcoholic steatohepatitis. Nat Rev Gastroenterol Hepatol 2019;16:145-159.

43. Carpino G, Del Ben M, Pastori D, Carnevale R, Baratta F, Overi D, et al. Increased liver localization of lipopolysaccharides in human and experimental NAFLD. Hepatology 2020;72:470-485.

44. Esparza-Baquer A, Labiano I, Sharif O, Agirre-Lizaso A, Oakley F, Rodrigues PM, et al. TREM-2 defends the liver against hepatocellular carcinoma through multifactorial protective mechanisms. Gut 2021;70:1345-1361.

45. Ramachandran P, Dobie R, Wilson-Kanamori JR, Dora EF, Henderson BEP, Luu NT, et al. Resolving the fibrotic niche of human liver cirrhosis at single-cell level. Nature 2019;575:512-518.

46. Mulder K, Patel AA, Kong WT, Piot C, Halitzki E, Dunsmore G, et al. Cross-tissue single-cell landscape of human monocytes and macrophages in health and disease. Immunity 2021;54:18831900.e5.

47. Sheng J, Zhang J, Wang L, Tano V, Tang J, Wang X, et al. Topological analysis of hepatocellular carcinoma tumour microenvironment based on imaging mass cytometry reveals cellular neighbourhood regulated reversely by macrophages with different ontogeny. Gut 2022;71:1176-1191.

48. Yao W, Ba Q, Li X, Li H, Zhang S, Yuan Y, et al. A natural CCR2 antagonist relieves tumor-associated macrophage-mediated immunosuppression to produce a therapeutic effect for liver cancer. EBioMedicine 2017;22:58-67.

49. Li X, Yao W, Yuan Y, Chen P, Li B, Li J, et al. Targeting of tumourinfiltrating macrophages via CCL2/CCR2 signalling as a 
therapeutic strategy against hepatocellular carcinoma. Gut 2017;66:157-167.

50. Teng KY, Han J, Zhang X, Hsu SH, He S, Wani NA, et al. Blocking the CCL2-CCR2 axis using CCL2-neutralizing antibody is an effective therapy for hepatocellular cancer in a mouse model. Mol Cancer Ther 2017;16:312-322.

51. Avila MA, Berasain C. Targeting CCL2/CCR2 in tumor-infiltrating macrophages: a tool emerging out of the box against hepatocellular carcinoma. Cell Mol Gastroenterol Hepatol 2019;7:293-294.

52. Noy R, Pollard JW. Tumor-associated macrophages: from mechanisms to therapy. Immunity 2014;41:49-61.

53. Wu J, Gao W, Tang Q, Yu Y, You W, Wu Z, et al. M2 macrophagederived exosomes facilitate HCC metastasis by transferring aM $\beta 2$ integrin to tumor cells. Hepatology 2021;73:1365-1380.

54. Song G, Shi Y, Zhang M, Goswami S, Afridi S, Meng L, et al. Global immune characterization of HBV/HCV-related hepatocellular carcinoma identifies macrophage and T-cell subsets associated with disease progression. Cell Discov 2020;6:90.

55. Chen DP, Ning WR, Jiang ZZ, Peng ZP, Zhu LY, Zhuang SM, et al. Glycolytic activation of peritumoral monocytes fosters immune privilege via the PFKFB3-PD-L1 axis in human hepatocellular carcinoma. J Hepatol 2019;71:333-343.

56. Chen DP, Ning WR, Li XF, Wei Y, Lao XM, Wang JC, et al. Peritumoral monocytes induce cancer cell autophagy to facilitate the progression of human hepatocellular carcinoma. Autophagy 2018;14:1335-1346.

57. Sung PS, Cho SW, Lee J, Yang H, Jang JW, Bae SH, et al. Infiltration of $\mathrm{t}$ cells and programmed cell death ligand 1-expressing macrophages as a potential predictor of lenvatinib response in hepatocellular carcinoma. J Liver Cancer 2020;20:128-134.

58. Lu LC, Lee YH, Chang CJ, Shun CT, Fang CY, Shao YY, et al. Increased expression of programmed death-ligand 1 in infiltrating immune cells in hepatocellular carcinoma tissues after sorafenib treatment. Liver Cancer 2019;8:110-120.

59. Park DJ, Sung PS, Kim JH, Lee GW, Jang JW, Jung ES, et al. EpCAM-high liver cancer stem cells resist natural killer cellmediated cytotoxicity by upregulating CEACAM1. J Immunother Cancer 2020;8:e000301.

60. Lee TK, Castilho A, Cheung VC, Tang KH, Ma S, Ng IO. CD24 liver tumor-initiating cells drive self-renewal and tumor initiation through STAT3-mediated NANOG regulation. Cell Stem Cell 2011;9:50-63.

61. Barkal AA, Brewer RE, Markovic M, Kowarsky M, Barkal SA, Zaro BW, et al. CD24 signalling through macrophage Siglec-10 is a target for cancer immunotherapy. Nature 2019;572:392-396.

62. Logtenberg MEW, Scheeren FA, Schumacher TN. The CD47SIRPa immune checkpoint. Immunity 2020;52:742-752.

63. Chen J, Zheng DX, Yu XJ, Sun HW, Xu YT, Zhang YJ, et al. Macrophages induce CD47 upregulation via IL- 6 and correlate with poor survival in hepatocellular carcinoma patients. Oncoimmunology 2019;8:e1652540.

64. Weiskopf K, Jahchan NS, Schnorr PJ, Cristea S, Ring AM, Maute $\mathrm{RL}$, et al. CD47-blocking immunotherapies stimulate macrophage-mediated destruction of small-cell lung cancer. J Clin Invest 2016;126:2610-2620.

65. Xiao Z, Chung H, Banan B, Manning PT, Ott KC, Lin S, et al. Antibody mediated therapy targeting CD47 inhibits tumor progression of hepatocellular carcinoma. Cancer Lett 2015;360:302-309.

66. Lo J, Lau EY, So FT, Lu P, Chan VS, Cheung VC, et al. Anti-CD47 antibody suppresses tumour growth and augments the effect of chemotherapy treatment in hepatocellular carcinoma. Liver Int 2016;36:737-745.

67. Tang KH, Ma S, Lee TK, Chan YP, Kwan PS, Tong CM, et al. CD133+ liver tumor-initiating cells promote tumor angiogenesis, growth, and self-renewal through neurotensin/interleukin-8/CXCL1 signaling. Hepatology 2012;55:807-820.

68. Xiao P, Long X, Zhang L, Ye Y, Guo J, Liu P, et al. Neurotensin/ IL-8 pathway orchestrates local inflammatory response and tumor invasion by inducing $\mathrm{M} 2$ polarization of tumor-associated macrophages and epithelial-mesenchymal transition of hepatocellular carcinoma cells. Oncoimmunology 2018;7:e1440166.

69. Lee TK, Guan XY, Ma S. Cancer stem cells in hepatocellular carcinoma - from origin to clinical implications. Nat Rev Gastroenterol Hepatol 2022;19:26-44.

70. Yin Z, Ma T, Lin Y, Lu X, Zhang C, Chen S, et al. IL-6/STAT3 pathway intermediates $\mathrm{M} 1 / \mathrm{M} 2$ macrophage polarization during the development of hepatocellular carcinoma. J Cell Biochem 2018;119:9419-9432.

71. Wan S, Zhao E, Kryczek I, Vatan L, Sadovskaya A, Ludema G, et al. Tumor-associated macrophages produce interleukin 6 and signal via STAT3 to promote expansion of human hepatocellular carcinoma stem cells. Gastroenterology 2014;147:13931404.

72. Chen Y, Wen H, Zhou C, Su Q, Lin Y, Xie Y, et al. TNF-a derived from M2 tumor-associated macrophages promotes epithelialmesenchymal transition and cancer stemness through the Wnt/ $\beta$-catenin pathway in SMMC-7721 hepatocellular carcinoma cells. Exp Cell Res 2019;378:41-50. 
73. Zhang J, Zhang Q, Lou Y, Fu Q, Chen Q, Wei T, et al. Hypoxiainducible factor-1a/interleukin-1 $\beta$ signaling enhances hepatoma epithelial-mesenchymal transition through macrophages in a hypoxic-inflammatory microenvironment. Hepatology 2018;67:1872-1889.

74. Fu XT, Dai Z, Song K, Zhang ZJ, Zhou ZJ, Zhou SL, et al. Macrophage-secreted IL-8 induces epithelial-mesenchymal transition in hepatocellular carcinoma cells by activating the JAK2/ STAT3/Snail pathway. Int J Oncol 2015;46:587-596.

75. Zhong CQ, Zhang XP, Ma N, Zhang EB, Li JJ, Jiang YB, et al. FABP4 suppresses proliferation and invasion of hepatocellular carcinoma cells and predicts a poor prognosis for hepatocellular carcinoma. Cancer Med 2018;7:2629-2640.

76. Fan QM, Jing YY, Yu GF, Kou XR, Ye F, Gao L, et al. Tumor-associated macrophages promote cancer stem cell-like properties via transforming growth factor-beta1-induced epithelialmesenchymal transition in hepatocellular carcinoma. Cancer Lett 2014;352:160-168.

77. Xue ST, Li K, Gao Y, Zhao LY, Gao Y, Yi H, et al. The role of the key autophagy kinase ULK1 in hepatocellular carcinoma and its validation as a treatment target. Autophagy 2020;16:18231837.

78. Fu XT, Song K, Zhou J, Shi YH, Liu WR, Shi GM, et al. Tumorassociated macrophages modulate resistance to oxaliplatin via inducing autophagy in hepatocellular carcinoma. Cancer Cell Int 2019;19:71.

79. Guo B, Li L, Guo J, Liu A, Wu J, Wang H, et al. M2 tumorassociated macrophages produce interleukin-17 to suppress oxaliplatin-induced apoptosis in hepatocellular carcinoma. Oncotarget 2017;8:44465-44476.

80. Sun K, Xu L, Jing Y, Han Z, Chen X, Cai C, et al. Autophagydeficient Kupffer cells promote tumorigenesis by enhancing mtROS-NF-KB-IL1a/ $\beta$-dependent inflammation and fibrosis during the preneoplastic stage of hepatocarcinogenesis. Cancer Lett 2017;388:198-207.

81. Deust A, Chobert MN, Demontant V, Gricourt G, Denaës T, Thiolat $A$, et al. Macrophage autophagy protects against hepatocellular carcinogenesis in mice. Sci Rep 2021;11:18809.

82. Liu LZ, Zhang Z, Zheng BH, Shi Y, Duan M, Ma LJ, et al. CCL15 recruits suppressive monocytes to facilitate immune escape and disease progression in hepatocellular carcinoma. Hepatology 2019;69:143-159.

83. He Q, Liu M, Huang W, Chen X, Zhang B, Zhang T, et al. IL-1 $\beta$ induced elevation of solute carrier family 7 member 11 promotes hepatocellular carcinoma metastasis through up-reg- ulating programmed death ligand 1 and colony-stimulating factor 1. Hepatology 2021;74:3174-3193.

84. Ke M, Zhang Z, Cong L, Zhao S, Li Y, Wang X, et al. MicroRNA-148b-colony-stimulating factor-1 signaling-induced tumor-associated macrophage infiltration promotes hepatocellular carcinoma metastasis. Biomed Pharmacother 2019;120:109523.

85. Chai ZT, Zhu XD, Ao JY, Wang WQ, Gao DM, Kong J, et al. MicroRNA-26a suppresses recruitment of macrophages by downregulating macrophage colony-stimulating factor expression through the PI3K/Akt pathway in hepatocellular carcinoma. J Hematol Oncol 2015;8:56.

86. Ao JY, Zhu XD, Chai ZT, Cai H, Zhang YY, Zhang KZ, et al. Colony-stimulating factor 1 receptor blockade inhibits tumor growth by altering the polarization of tumor-associated macrophages in hepatocellular carcinoma. Mol Cancer Ther 2017;16:1544-1554.

87. Zhu Y, Yang J, Xu D, Gao XM, Zhang Z, Hsu JL, et al. Disruption of tumour-associated macrophage trafficking by the osteopontin-induced colony-stimulating factor-1 signalling sensitises hepatocellular carcinoma to anti-PD-L1 blockade. Gut 2019;68:1653-1666.

88. Wang Y, Wang B, Xiao S, Li Y, Chen Q. MiR-125a/b inhibits tumor-associated macrophages mediated in cancer stem cells of hepatocellular carcinoma by targeting CD90. J Cell Biochem 2019;120:3046-3055.

89. Liu J, Fan L, Yu H, Zhang J, He Y, Feng D, et al. Endoplasmic reticulum stress causes liver cancer cells to release exosomal miR-23a-3p and up-regulate programmed death ligand 1 expression in macrophages. Hepatology 2019;70:241-258.

90. Yin C, Han Q, Xu D, Zheng B, Zhao X, Zhang J. SALL4-mediated upregulation of exosomal miR-146a-5p drives T-cell exhaustion by $\mathrm{M} 2$ tumor-associated macrophages in HCC. Oncoimmunology 2019;8:1601479.

91. Sung PS, Jang JW. Natural killer cell dysfunction in hepatocelIular carcinoma: pathogenesis and clinical implications. Int J Mol Sci 2018;19:3648.

92. Wu Y, Kuang DM, Pan WD, Wan YL, Lao XM, Wang D, et al. Monocyte/macrophage-elicited natural killer cell dysfunction in hepatocellular carcinoma is mediated by CD48/2B4 interactions. Hepatology 2013;57:1107-1116.

93. Ma PF, Gao CC, Yi J, Zhao JL, Liang SQ, Zhao Y, et al. Cytotherapy with M1-polarized macrophages ameliorates liver fibrosis by modulating immune microenvironment in mice. J Hepatol 2017;67:770-779. 
94. Kuang DM, Zhao Q, Peng C, Xu J, Zhang JP, Wu C, et al. ACtivated monocytes in peritumoral stroma of hepatocellular carcinoma foster immune privilege and disease progression through PD-L1. J Exp Med 2009;206:1327-1337.

95. Wu K, Kryczek I, Chen L, Zou W, Welling TH. Kupffer cell suppression of CD8+ T cells in human hepatocellular carcinoma is mediated by B7-H1/programmed death-1 interactions. Cancer Res 2009;69:8067-8075.

96. Ma J, Zheng B, Goswami S, Meng L, Zhang D, Cao C, et al. PD1 ${ }^{\mathrm{Hi}}$ $\mathrm{CD}^{+} \mathrm{T}$ cells correlate with exhausted signature and poor clinical outcome in hepatocellular carcinoma. J Immunother Cancer 2019;7:331.

97. Petty AJ, Dai R, Lapalombella R, Baiocchi RA, Benson DM, Li Z, et al. Hedgehog-induced PD-L1 on tumor-associated macrophages is critical for suppression of tumor-infiltrating $\mathrm{CD}^{+} \mathrm{T}$ cell function. JCl Insight 2021;6:e146707.

98. Chamseddine AN, Assi T, Mir O, Chouaib S. Modulating tumorassociated macrophages to enhance the efficacy of immune checkpoint inhibitors: a TAM-pting approach. Pharmacol Ther 2022;231:107986

99. Chen $\mathrm{CL}$, Hsu SC, Ann DK, Yen Y, Kung HJ. Arginine signaling and cancer metabolism. Cancers (Basel) 2021;13:3541.

100. Pan Y, Yu Y, Wang X, Zhang T. Tumor-associated macrophages in tumor immunity. Front Immunol 2020;11:583084.

101. Geiger R, Rieckmann JC, Wolf T, Basso C, Feng Y, Fuhrer T, et al. L-arginine modulates $\mathrm{T}$ cell metabolism and enhances survival and anti-tumor activity. Cell 2016;167:829-842.e13.

102. Kaneda MM, Messer KS, Ralainirina N, Li H, Leem CJ, Gorjestani $\mathrm{S}$, et al. PI3KY is a molecular switch that controls immune suppression. Nature 2016;539:437-442.

103. De Henau O, Rausch M, Winkler D, Campesato LF, Liu C, Cymerman $\mathrm{DH}$, et al. Overcoming resistance to checkpoint blockade therapy by targeting PI3KY in myeloid cells. Nature 2016;539:443-447.

104. Sung PS, Cheon H, Cho CH, Hong SH, Park DY, Seo HI, et al. Roles of unphosphorylated ISGF3 in HCV infection and interferon responsiveness. Proc Natl Acad Sci U S A 2015;112:1044310448.

105. Sung PS, Shin EC. Interferon response in hepatitis $C$ virusinfected hepatocytes: issues to consider in the era of directacting antivirals. Int J Mol Sci 2020;21:2583.

106. Lund Laursen T, Brøckner Siggard C, Kazankov K, Damgaard Sandahl T, Møller HJ, Ong A, et al. Rapid and persistent decline in soluble CD163 with successful direct-acting antiviral therapy and associations with chronic hepatitis C histology. Scand J
Gastroenterol 2018:53:986-993.

107. Bolte FJ, O'Keefe AC, Webb LM, Serti E, Rivera E, Liang TJ, et al. Intra-hepatic depletion of mucosal-associated invariant T cells in hepatitis c virus-induced liver inflammation. Gastroenterology 2017;153:1392-1403.e2.

108. Carlin AF, Aristizabal P, Song Q, Wang H, Paulson MS, Stamm LM, et al. Temporal dynamics of inflammatory cytokines/chemokines during sofosbuvir and ribavirin therapy for genotype 2 and 3 hepatitis C infection. Hepatology 2015;62:1047-1058.

109. Spaan M, van Oord G, Kreefft K, Hou J, Hansen BE, Janssen HL, et al. Immunological analysis during interferon-free therapy for chronic hepatitis $C$ virus infection reveals modulation of the natural killer cell compartment. J Infect Dis 2016;213:216223.

110. Xiang $X$, Wang J, Lu D, Xu X. Targeting tumor-associated macrophages to synergize tumor immunotherapy. Signal Transduct Target Ther 2021;6:75.

111. Yu S, Wang Y, Hou J, Li W, Wang X, Xiang L, et al. Tumor-infiltrating immune cells in hepatocellular carcinoma: Tregs is correlated with poor overall survival. PLoS One 2020;15:e0231003.

112. Wu Q, Zhou W, Yin S, Zhou Y, Chen T, Qian J, et al. Blocking triggering receptor expressed on myeloid cells-1-positive tumor-associated macrophages induced by hypoxia reverses immunosuppression and anti-programmed cell death ligand 1 resistance in liver cancer. Hepatology 2019;70:198-214.

113. Liu C, Chikina M, Deshpande R, Menk AV, Wang T, Tabib T, et al. Treg cells promote the SREBP1-dependent metabolic fitness of tumor-promoting macrophages via repression of $\mathrm{CD} 8^{+} \mathrm{T}$ cellderived interferon- $\gamma$. Immunity 2019;51:381-397.e6.

114. Ringelhan M, Pfister D, O'Connor T, Pikarsky E, Heikenwalder M. The immunology of hepatocellular carcinoma. Nat Immunol 2018;19:222-232.

115. Chen MM, Xiao X, Lao XM, Wei Y, Liu RX, Zeng QH, et al. Polarization of tissue-resident TFH-like cells in human hepatoma bridges innate monocyte inflammation and M2b macrophage polarization. Cancer Discov 2016;6:1182-1195.

116. Shalapour S, Lin XJ, Bastian IN, Brain J, Burt AD, Aksenov AA, et al. Inflammation-induced $\lg A^{+}$cells dismantle anti-liver cancer immunity. Nature 2017;551:340-345.

117. Sung PS, Yoon SK, Jang JW, Lee SK, Yang H. Inflammationinduced IgA plus tumor-associated macrophages express PDL1 and causes impaired T cell functionality in hepatocellular carcinoma. Hepatology 2022;72:780A-781A.

118. Arvanitakis K, Mitroulis I, Germanidis G. Tumor-associated neutrophils in hepatocellular carcinoma pathogenesis, prognosis, 
and therapy. Cancers (Basel) 2021;13:2899.

119. Peng ZP, Jiang ZZ, Guo HF, Zhou MM, Huang YF, Ning WR, et al. Glycolytic activation of monocytes regulates the accumulation and function of neutrophils in human hepatocellular carcinoma. J Hepatol 2020;73:906-917.

120. Zhou SL, Zhou ZJ, Hu ZQ, Huang XW, Wang Z, Chen EB, et al. Tumor-associated neutrophils recruit macrophages and Tregulatory cells to promote progression of hepatocellular carcinoma and resistance to sorafenib. Gastroenterology 2016;150:1646-1658.e17.

121. Zhou SL, Dai Z, Zhou ZJ, Wang XY, Yang GH, Wang Z, et al. Overexpression of CXCL5 mediates neutrophil infiltration and indicates poor prognosis for hepatocellular carcinoma. Hepatology 2012;56:2242-2254.

122. Singh P, Toom S, Avula A, Kumar V, Rahma OE. The immune modulation effect of locoregional therapies and its potential synergy with immunotherapy in hepatocellular carcinoma. J Hepatocell Carcinoma 2020;7:11-17.

123. Chew V, Lee YH, Pan L, Nasir NJM, Lim CJ, Chua C, et al. Immune activation underlies a sustained clinical response to $\mathrm{Yt}$ trium-90 radioembolisation in hepatocellular carcinoma. Gut 2019;68:335-346.

124. Kang BY, Kim SM, Hur W, Roh PR, Han JW, Sung PS, et al. Phenylboronic acid conjugated to doxorubicin for the treatment of hepatocellular carcinoma through transcatheter arterial chemoembolization. Research Square web stie, <https:// doi.org/10.21203/rs.3.rs-858146/v1>. Accessed 1 Sep 2021.

125. Chung YH, Yu CF, Chiu SC, Chiu H, Hsu ST, Wu CR, et al. Diffusion-weighted MRI and 18F-FDG PET correlation with immunity in early radiotherapy response in BNL hepatocellular carcinoma mouse model: timeline validation. Eur J Nucl Med Mol Imaging 2019;46:1733-1744.

126. Jeong KY, Lee EJ, Yang SH, Seong J. Combination of macrophage inflammatory protein 1 alpha with existing therapies to enhance the antitumor effects on murine hepatoma. J Radiat Res 2015;56:37-45.

127. Choi C, Yoo GS, Cho WK, Park HC. Optimizing radiotherapy with immune checkpoint blockade in hepatocellular carcinoma. World J Gastroenterol 2019;25:2416-2429.

128. Yoo GS, Ahn WG, Kim SY, Kang W, Choi C, Park HC. Radiationinduced abscopal effect and its enhancement by programmed cell death 1 blockade in the hepatocellular carcinoma: a murine model study. Clin Mol Hepatol 2021;27:144-156.

129. Kim HJ, Park S, Kim KJ, Seong J. Clinical significance of soluble programmed cell death ligand-1 (sPD-L1) in hepatocellular car- cinoma patients treated with radiotherapy. Radiother Oncol 2018;129:130-135.

130. Kudo M, Finn RS, Qin S, Han KH, Ikeda K, Piscaglia F, et al. Lenvatinib versus sorafenib in first-line treatment of patients with unresectable hepatocellular carcinoma: a randomised phase 3 non-inferiority trial. Lancet 2018;391:1163-1173.

131. Lee J, Han JW, Sung PS, Lee SK, Yang H, Nam HC, et al. Comparative analysis of lenvatinib and hepatic arterial infusion chemotherapy in unresectable hepatocellular carcinoma: a multi-center, propensity score study. J Clin Med 2021;10:4045.

132. Lee J, Sung PS, Yang H, Lee SK, Nam HC, Yoo SH, et al. A realworld comparative analysis of lenvatinib and sorafenib as a salvage therapy for transarterial treatments in unresectable HCC. J Clin Med 2020;9:4121.

133. Kimura T, Kato Y, Ozawa Y, Kodama K, Ito J, Ichikawa K, et al. Immunomodulatory activity of lenvatinib contributes to antitumor activity in the Hepa1-6 hepatocellular carcinoma model. Cancer Sci 2018;109:3993-4002.

134. Yi C, Chen L, Lin Z, Liu L, Shao W, Zhang R, et al. Lenvatinib targets FGF receptor 4 to enhance antitumor immune response of anti-programmed cell death-1 in HCC. Hepatology 2021;74:2544-2560.

135. Dong N, Shi X, Wang S, Gao Y, Kuang Z, Xie Q, et al. M2 macrophages mediate sorafenib resistance by secreting HGF in a feed-forward manner in hepatocellular carcinoma. Br J Cancer 2019;121:22-33.

136. Chen Y, Ramjiawan RR, Reiberger T, Ng MR, Hato T, Huang $Y$, et al. CXCR4 inhibition in tumor microenvironment facilitates anti-programmed death receptor-1 immunotherapy in sorafenib-treated hepatocellular carcinoma in mice. Hepatology 2015;61:1591-1602.

137. Chen Y, Huang Y, Reiberger T, Duyverman AM, Huang P, Samuel $R$, et al. Differential effects of sorafenib on liver versus tumor fibrosis mediated by stromal-derived factor 1 alpha/C-X-C receptor type 4 axis and myeloid differentiation antigen-positive myeloid cell infiltration in mice. Hepatology 2014;59:1435-1447.

138. Ou DL, Chen CW, Hsu CL, Chung CH, Feng ZR, Lee BS, et al. Regorafenib enhances antitumor immunity via inhibition of p38 kinase/Creb1/KIf4 axis in tumor-associated macrophages. J Immunother Cancer 2021;9:e001657.

139. Granito A, Marinelli S, Forgione A, Renzulli M, Benevento F, Piscaglia $F$, et al. Regorafenib combined with other systemic therapies: exploring promising therapeutic combinations in HCC. J Hepatocell Carcinoma 2021;8:477-492.

140. Shang R, Song X, Wang P, Zhou Y, Lu X, Wang J, et al. Cabozan- 
tinib-based combination therapy for the treatment of hepatocellular carcinoma. Gut 2021;70:1746-1757.

141. Ma L, Wang L, Khatib SA, Chang CW, Heinrich S, Dominguez $D A$, et al. Single-cell atlas of tumor cell evolution in response to therapy in hepatocellular carcinoma and intrahepatic cholangiocarcinoma. J Hepatol 2021;75:1397-1408.

142. Lin C, He H, Liu H, Li R, Chen Y, Qi Y, et al. Tumour-associated macrophages-derived CXCL8 determines immune evasion through autonomous PD-L1 expression in gastric cancer. Gut 2019;68:1764-1773.

143. Zong Z, Zou J, Mao R, Ma C, Li N, Wang J, et al. M1 macrophages induce PD-L1 expression in hepatocellular carcinoma cells through IL-1 $\beta$ signaling. Front Immunol 2019;10:1643.

144. Jansen CS, Prokhnevska N, Master VA, Sanda MG, Carlisle JW, Bilen MA, et al. An intra-tumoral niche maintains and differentiates stem-like CD8 T cells. Nature 2019;576:465-470.

145. Yan W, Liu X, Ma H, Zhang H, Song X, Gao L, et al. Tim-3 fosters HCC development by enhancing TGF- $\beta$-mediated alternative activation of macrophages. Gut 2015;64:1593-1604.

146. Li J, Lee Y, Li Y, Jiang Y, Lu H, Zang W, et al. Co-inhibitory molecule B7 superfamily member 1 expressed by tumor-infiltrating myeloid cells induces dysfunction of anti-tumor CD8+ T cells. Immunity 2018;48:773-786.e5.

147. Li G, Liu D, Kimchi ET, Kaifi JT, Qi X, Manjunath Y, et al. Nanoliposome C6-ceramide increases the anti-tumor immune response and slows growth of liver tumors in mice. Gastroenterology 2018;154:1024-1036.e9.

148. Wang B, Li Q, Qin L, Zhao S, Wang J, Chen X. Transition of tumor-associated macrophages from MHC class II(hi) to MHC class II(low) mediates tumor progression in mice. BMC Immunol 2011;12:43.

149. Zhou DY, Qin J, Huang J, Wang F, Xu GP, Lv YT, et al. Zoledronic acid inhibits infiltration of tumor-associated macrophages and angiogenesis following transcatheter arterial chemoembolization in rat hepatocellular carcinoma models. Oncol Lett 2017; 14:4078-4084. 